\title{
Possível transmissão de mãe para filho da covid-19 através da amamentação
}

\author{
Possible transmission from mother to child at covid-19 through breastfeeding \\ Posible transmisión de madre a hijo en covid-19 mediante lactancia
}

Recebido: 18/11/2021 | Revisado: 22/11/2021 | Aceito: 17/12/2021 | Publicado: 20/12/2021

\author{
Valdislaynner Khimberly do Nascimento Santos \\ ORCID: https://orcid.org/0000-0002-8644-5195 \\ Faculdade de Comunicação Tecnologia e Turismo de Olinda, Brasil \\ E-mail: laynnersantos@gmail.com \\ Danielle Cássia de Oliveira \\ ORCID: https://orcid.org/0000-0003-4154-2597 \\ Faculdade de Comunicação Tecnologia e Turismo de Olinda, Brasil \\ E-mail: danielle.oliveira@prof.facottur.org \\ Alisse Maria Chaves de Lima Peixoto \\ ORCID: https://orcid.org/0000-0003-2430-6031 \\ Universidade de Pernambuco, Brasil \\ E-mail: alissepeixoto@gmail.com \\ Lívia Almeida Amaral Ferraz \\ ORCID: https://orcid.org/0000-0002-9665-8450 \\ Faculdade de Comunicação Tecnologia e Turismo de Olinda, Brasil \\ E-mail: liviaalmeida-@hotmail.com
}

\begin{abstract}
Resumo
Com a propagação alta e rápida da covid-19 na população, algumas preocupações foram levantadas, como a segurança de mulheres grávidas e que estão no período de amamentação. Essa atenção é sobre a possível transmissão de mãe para filho através do leite materno. Objetivo: verificar a possibilidade de uma possível transmissão de mãe para filho através do leite materno. Métodos: A buscas de artigos foi realizada nas bases de dados eletrônicos Scielo, Pubmed e Lilacs. Para a busca de artigos foram utilizadas palavras-chave "amamentação", "leite materno" e "covid19", a busca na literatura se deu nos últimos 3 anos. Resultados: Ao realizar a triagem utilizando os critérios de inclusão, tem-se para estudo um total de 8 artigos, onde $50 \%$ destes artigos apresentaram amostras negativas do SARS-CoV-2 nos leites maternos, enquanto os outros $50 \%$ identificaram o SARS-CoV-2 presentes em ao menos 1 amostra de leite materno. Conclusão: Os estudos abordados nesta revisão revelaram que o aleitamento materno não é considerado um meio de transmissão vertical para o coronavírus.
\end{abstract}

Palavras-chave: Covid-19; Leite materno; Amamentação.

\begin{abstract}
With the high and fast spread of the covid-19 in the population, some worries has been raised, like the safety of pregnant women and that are in breastfeeding. This attention is about the possible transmission from mother to son through breast milk. Objective: verify the possibility of a possible transmission from mother to son through breast milk. Methods: the articles searches were done at the electronics databases SciELO, PubMed and Lilacs. For the articles searches were used selected descriptors through consultations to the DECS (subjects descriptors in health science of BIREME), being them "breastfeeding", "breast milk" and "covid-19", the search in the literature was in the last three years. Results: when performing the screening using the inclusion criteria, there is for study a total of eight articles, where $50 \%$ of these articles showed negative samples of SARS-CoV-2 in the breast milk, whilst the others $50 \%$ recognize the SARS-CoV-2 presents in at least one sample of breast milk. Conclusion: the studies covered in this review showed that breastfeeding is not considered a vertical transmission medium for the coronavirus.
\end{abstract}

Keywords: Covid-19; Breast milk; Breast-feeding.

\section{Resumen}

Con la alta y rápida propagación del covid-19 en la población, se han planteado algunas preocupaciones, como la seguridad de las mujeres embarazadas y lactantes. Esta atención se centra en la posible transmisión de madre a hijo a través de la leche materna. Objetivo: verificar la posibilidad de una posible transmisión maternoinfantil a través de la leche materna. Métodos: Se realizaron búsquedas de artículos en las bases de datos electrónicas Scielo, Pubmed y Lilacs. Para la búsqueda de artículos se utilizaron las palabras clave "lactancia materna", "leche materna" y "covid19”, la búsqueda bibliográfica se realizó en los últimos 3 años. Resultados: Al realizar el cribado con los criterios de inclusión, se estudiaron un total de 8 artículos, donde el $50 \%$ de estos artículos presentaron muestras negativas de SARS-CoV-2 en la leche materna, mientras que el otro 50\% identificó SARS-CoV-2 presente en al menos 1 muestra 
de leche materna. Conclusión: Los estudios cubiertos en esta revisión revelaron que la lactancia materna no se considera un medio de transmisión vertical del coronavirus.

Palabras clave: Covid-19; Leche materna; Amamantamiento.

\section{Introdução}

O novo vírus SARS-CoV-2 denominado como coronavírus, causador da covid-19 surgiu em Wuhan, província de Hubei na China no final de 2019. Devido ao seu alto poder de transmissão e altas chances de complicações, como uma delas a infecção respiratória aguda, o mesmo ocasionou uma pandemia com altas taxas de contaminação e mortalidade ao redor do mundo (Ahn et al., 2020).

De acordo com os dados da Organização Mundial de Saúde (OMS), atualizados em 11 de maio de 2021, globalmente houve mais de 162 milhões de casos confirmados e mais de 3 milhões de mortes. A incidência de casos e de mortalidade, permanecem em níveis altos desde o início da pandemia (OMS., 2021).

A transmissão do SARS-CoV-2 ocorre por meio de gotículas respiratórias, produzidas quando uma pessoa que está infectada tosse ou espirra. Os sintomas clínicos mais predominantes são cansaço, febre e tosse seca, entretanto, algumas pessoas podem apresentar outros sintomas característicos como, por exemplo, anosmia, ageusia. Observa-se que pessoas portadoras de comorbidades como diabetes, problemas cardiovasculares, hipertensão arterial, neoplasias entre outros, podem apresentar quadros mais graves como pneumonia, doenças do trato respiratório e muitas vezes podem evoluir para a morte (Bi, Qifang et al., 2020; OMS., 2020).

Com a propagação alta e rápida da covid-19 na população, algumas preocupações foram levantadas, como a segurança de mulheres grávidas e que estão no período de amamentação. Essa atenção é sobre a possível transmissão de mãe para filho através do leite materno (LM) (Pace et al., 2021).

É inquestionável a superioridade do LM (Keppler., 2020), sendo um alimento completo composto por quantidades adequadas de nutrientes que são suficientes para o bebê, e por fatores imunológicos que os protegem de alergias e infecções. Mais benefícios são atribuídos ao LM para a criança, servindo como base para desenvolvimento futuro da mesma. Diante de seus benefícios já elucidados na literatura, é recomendado que o aleitamento materno seja feito exclusivamente até os seis meses de vida, e que após esse período seja continuado por pelo menos até 2 anos ou mais (Brasil., 2015).

Mesmo com o conhecimento da superioridade do LM, há um cuidado em relação à amamentação nesse período de pandemia, visto que é preciso aprofundar-se sobre a possível transmissão vertical da covid-19. Diante disso o presente trabalho tem como objetivo analisar a possível transmissão do coronavírus através da amamentação.

\section{Metodologia}

O presente trabalho trata-se de uma revisão integrativa da literatura, com buscas de artigos nas bases de dados eletrônicos Scielo, Pubmed e Lilacs, no período de março a junho de 2021. Para a busca de artigos foram utilizadas as palavras-chaves "amamentação", "leite materno" e "covid-19". Devido o tema ser novo, a busca na literatura foi de 2019 a 2021.

Foram considerados como critérios de inclusão artigos originais escritos em língua inglesa, portuguesa ou espanhola que abordassem o tema em questão. Como critérios de exclusão consideraram, artigos de revisão, artigos em duplicatas e artigos que não atendessem aos critérios de inclusão pré-estabelecidos. Para seleção dos artigos selecionados, foram primeiramente analisados o título, após isso foram analisados os resumos dos artigos incluídos e por fim os artigos foram lidos e analisados por completo, sendo assim incluídos ou excluídos. Este processo pode ser visualizado na Figura 1.

Figura 1 - Fluxograma. 


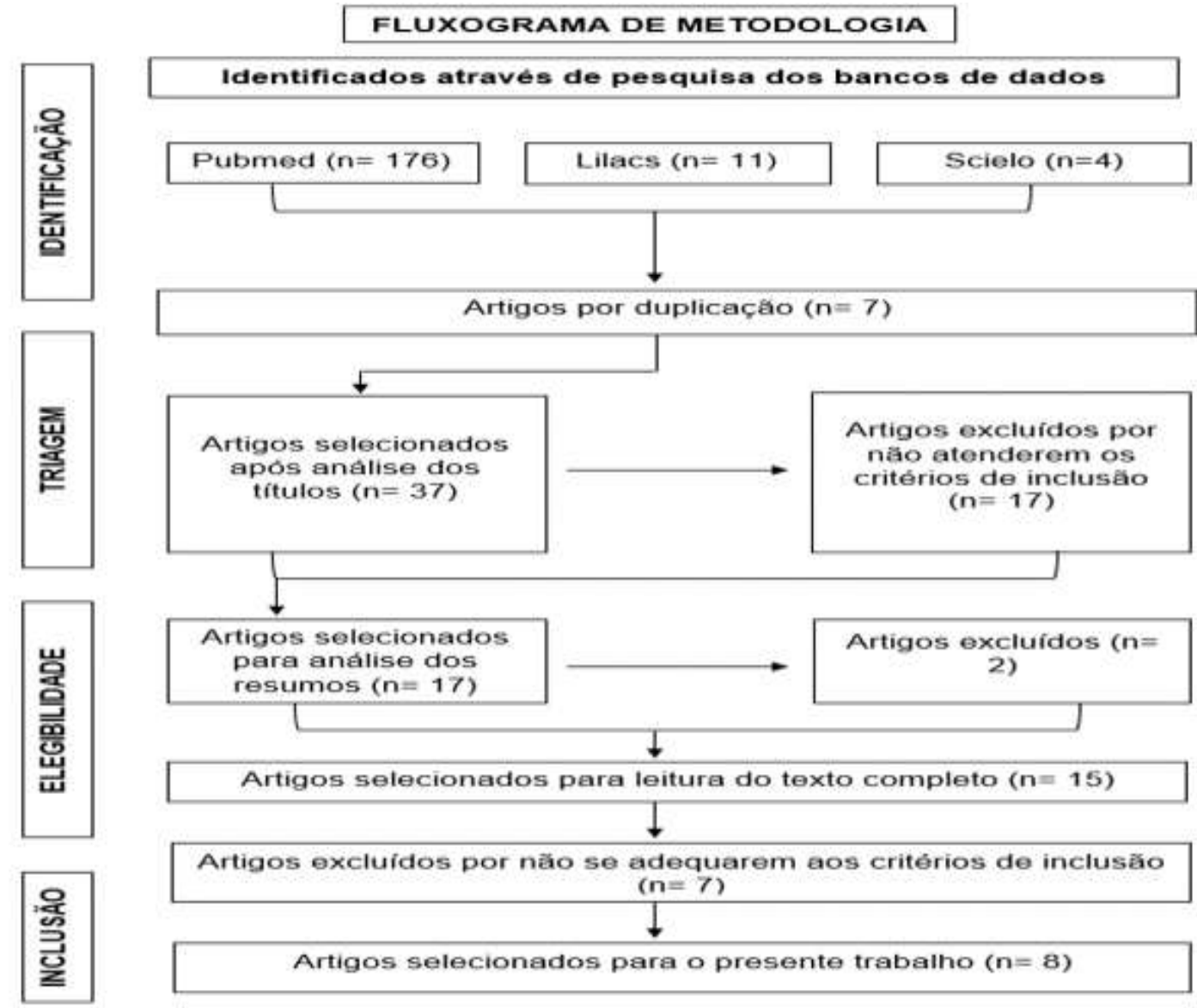

Fonte: Autores.

\section{Resultados}

Ao realizar a triagem utilizando os critérios de inclusão, tem-se para estudo um total de 8 artigos incluídos na amostra, 12,5\% dos artigos tinham como objetivo analisar se as mães testadas positivo para o coronavírus pode transmitir o vírus para o leite colostro extraído manualmente, $12,5 \%$ tinham como objetivo investigar as características clinicas de bebês nascidos de mães infectadas com o coronavírus, $12,5 \%$ tinham como objetivo analisar as características clinicas de mulheres no pré-parto e no pós-parto, 12,5\% tinham como objetivo descobrir se a transmissão da covid-19 pode ocorrer durante a amamentação e 50\% tinham como objetivo avaliar a presenta de SARS-oV-2 no leite materno. Os pontos particulares de cada estudo, estão dispostos na Tabela 1 .

Dentre os 8 artigos utilizados no presente trabalho, (50\%) apresentaram amostras negativas do SARS-CoV-2 nos leites maternos, enquanto os outros 50\% identificaram o SARS-CoV-2 presentes em ao menos 1 amostra de leite materno. Uma pesquisa identificou a presença de anticorpos específicos para o SARS-CoV-2. A maioria dos estudos foram realizados na China e nos Estados Unidos. 
Tabela 1. Descrição metodológica dos artigos incluídos na amostra final.

\begin{tabular}{|c|c|c|c|c|}
\hline AUTOR/ANO & OBEJTIVO & AMOSTRA & LOCAL & RESULTADOS \\
\hline $\begin{array}{l}\text { Marín Gabriel et } \\
\text { al. } 2020\end{array}$ & $\begin{array}{l}\text { Determinar se as mães } \\
\text { SARS-CoV-2 positivas } \\
\text { transmitem o vírus para o } \\
\text { colostro extraindo } \\
\text { manualmente }\end{array}$ & 7 & Espanha & $\begin{array}{l}\text { O SARS-CoV-2 não foi detectado em } \\
\text { nenhuma das amostras de colostro } \\
\text { obtidas no estudo. }\end{array}$ \\
\hline $\begin{array}{l}\text { Liu et al. } \\
2020\end{array}$ & $\begin{array}{l}\text { Investigar as características } \\
\text { clínicas de neonatos } \\
\text { nascidos de mães infectadas } \\
\text { com o SARS-CoV-2 }\end{array}$ & 10 & China & $\begin{array}{l}\text { Esfregaço de garganta, urina e fezes de } \\
\text { todos os neonatos foram negativos. } \\
\text { SARS-CoV-2 RT-PCR no leite materno } \\
\text { e líquido amniótico também deu } \\
\text { negativo. }\end{array}$ \\
\hline $\begin{array}{l}\text { Chen et al. } \\
2020\end{array}$ & $\begin{array}{l}\text { Analisar as características } \\
\text { clínicas de mulheres } \\
\text { grávidas com a doença } \\
\text { assim como a dos neonatos }\end{array}$ & 3 & China & $\begin{array}{l}\text { O teste para SARS-CoV-2 foi realizado } \\
\text { em esfregaços neonatais da garganta de } 8 \\
\text { recém-nascidos e amostras de leite } \\
\text { materno de } 3 \text { mães. Nenhum resultado } \\
\text { positivo foi relatado. }\end{array}$ \\
\hline $\begin{array}{l}\text { Bertino et al. } \\
2020\end{array}$ & $\begin{array}{l}\text { Verificar a presença de } \\
\text { RNA SARS-CoV-2 no leite } \\
\text { de um grupo de mães }\end{array}$ & 14 & Itália & $\begin{array}{l}\text { Em } 13 \text { casos, a pesquisa de RNA de } \\
\text { SARS-CoV-2 em amostras de leite foi } \\
\text { negativa e em um caso foi positiva. }\end{array}$ \\
\hline
\end{tabular}

CoV-2

Chambers et al. 2020

Wu et al.

2020

Krogstad et al. 2021

Pace et al. 2020 de mãe para filho do SARSCoV-2 pode ocorrer durante a amamentação.

Avaliar a presença do
Investigar se a transmissão

Avaliar se as secreções vaginais e o leite materno de mulheres com a Covid19 continham RNA de SARS-CoV-2 SARS-CoV-2 no leite materno de mulheres infectadas com o coronavírus
Embora o ARN do SARS-CoV-2 tenha sido detectado em 1 amostra de leite de uma mulher infectada, a cultura viral para essa amostra foi negativa. Estes dados sugerem que o ARN da SARSCoV-2 não representa o vírus competente para a replicação e que o leite materno pode não ser uma fonte de infecção para o lactente.

China Todas as 13 amostras de secreção vaginal, cinco esfregaços da garganta e quatro esfregaços anais coletados de neonatos foram negativos para o novo coronavírus. No entanto, uma das três amostras de leite materno foi positiva no teste de ácido nucleico viral.

Embora o vRNA do SARS-CoV-2 tenha sido detectado no leite de 7 de $110(6 \%)$ mulheres com infecção confirmada ou doença sintomática, e em 6 de 65 (9\%) das mulheres com SARS-CoV-2 positivo, o vírus não foi detectado em nenhuma cultura. Nenhuma das 7 amostras de leite com vRNA detectável continha sgRNA.

Não foi detectado RNA do SARS-CoV-2 em nenhuma amostra de leite. Em contraste, o ARN da SARS-CoV-2 foi detectado em vários esfregaços da mama, embora apenas um tenha sido 
considerado conclusivo. Todo o leite continha $\operatorname{Ig} \mathrm{A}$ e $\operatorname{IgG}$ específicos para SARS-CoV-2, e os níveis de IgA antiRBD correlacionados com a neutralização de SARS-CoV-2. Fortes correlações entre os níveis de IgA e IgG para SARS-CoV-2 e coronavírus sazonais foram observadas.

Fonte: Autores.

\section{Discussão}

Os estudos em geral mostraram que apesar de serem detectados RNA de SARS-CoV-2 nos leites materno, o mesmo não é viável à infecção mostrando resultados negativos no leite após 2 ou 3 dias, podendo-se assim dizer que não é possível a transmissão da covid-19 de mãe para filho através do leite materno, porém essa transmissão pode ocorrer por meio do contato do bebê com a mama se a mesma não for bem higienizada antes da oferta do leite. Alguns pesquisadores acreditam que por não haver muitos estudos sobre o assunto ainda é preciso que haja uma ponderação com a amamentação, por isso alguns desses pesquisadores não apoiam a amamentação como meio de precaução (Favre et al., 2020).

A OMS (2020), no entanto, afirma que não existem razões para a interrupção do aleitamento, pois o mesmo proporciona vantagens tanto para o bebê quanto para a mãe, levando em consideração que as mães devem tomar os devidos cuidados na hora da oferta desse leite materno, fazendo a higienização adequada tanto das mãos quanto da mama e sempre fazendo uso de mascaras. Sabemos que a interrupção do aleitamento materno poderia expor o bebê a um maior risco de infecções com probabilidade maiores de causar doenças graves (Keppler et al., 2020).

Marín Gabriel et al. (2020) testaram 7 amostras de leite colostro obtido de mães nas primeiras horas pós-parto, a coleta foi feita após a higienização devida das mãos e das mamas. Os testes apresentaram resultados negativos para todas as amostras, apontando a não presença do vírus no leite materno. O mesmo ocorreu no estudo de Chen et al. (2020) o qual realizou o teste em amostras de leite de mães com covid-19 e os mesmos mostraram que o leite materno não foi uma fonte de transmissão. Além disso, em mulheres que testaram positivo para o covid-19, também dispuseram de resultados negativos para todas as amostras (Liu et al., 2020).

No entanto Bertino et al. (2020) realizou testes em amostras de leite coletado de mães contaminadas pelo coronavírus, identificaram o RNA do SARS-CoV-2 em 14,2\% das amostras. Porém esse estudo utilizou vários métodos diferentes para a coleta do leite materno, havendo variação de local, manuseio e técnicas de extração, que pode ter influenciado o resultado final.

Em uma outra pesquisa que tinha como objetivo avaliar a presença do vírus no leite materno, também foi detectado resultado positivo para o SARS-CoV-2 na amostra de leite materno (Chambers et al., 2020). No entanto não foi relatado o procedimento detalhado realizado para a obtenção da amostra. Além disso, por mais que o SARS-CoV-2 tenha sido detectado em algumas das amostras, os pesquisadores apontam que a cultura viral para a mesma foi negativa, o que sugere que o SARSCoV-2 não simboliza o vírus apto a replicação.

Diferente do estudo anterior, Wu et al. (2020) também identificou RNA do SARS-CoV-2 no leite de uma das pacientes voluntárias para o estudo, entretanto $\mathrm{Wu}$ detalha a forma da coleta das amostras do leite, que ocorreu após a higienização adequada das mamas. O resultado deu positivo apenas no primeiro teste que foi realizado no primeiro dia pósparto, não tendo resultado positivo no segundo teste realizado após o terceiro dia pós-parto. Assim como no estudo de 
Chambers et al. (2020) as culturas virais encontradas nos leites que testaram positivo também sugere que o SARS-CoV-2 não apresenta perigo para contaminação.

Krogstad et al. (2021) resultou na detecção do RNA do SARS-CoV-2 no leite de 10,6\% das mulheres. Assim como o estudo de Chambers et al. (2020) os leites testados não apresentaram indicadores potenciais de replicação do vírus, tal como o estudo de $\mathrm{Wu}$ et al. (2020) as amostras disponíveis após os leites positivos também testaram negativo.

Além de analisar a presença de RNA positivos para o SARS-CoV-2, uma pesquisa também analisou se as amostras de leite materno possuíam anticorpos específicos para a covid-19 e a capacidade neutralizadora da mesma (Pace et al., 2020). Os testes revelaram que nenhuma amostra de leite continha RNA detectável de SARS-CoV-2, porém, foi detectado evidências de RNA do SARS-Cov-2 em esfregaços da mama realizados em uma das participantes antes da higienização, entretanto não ficou totalmente claro se esse RNA é viável. No esfregaço coletado após a devida higienização da mama, não continha presença de RNA do SARS-CoV-2, por isso a importância de uma correta higienização antes do ato de amamentar. Além disso, foi observado que os leites coletados continham IgA e IgG anti-SARS-CoV-2 e a capacidade neutralizadoras dos leites. Diferentes dos demais, que deixam lacunas no método de coleta, o estudo de Pace et al. (2020), detalha bem a aplicação dessa etapa, além de serem os primeiros a relatarem que o leite produzido por mulheres infectadas com covid-19 tem eficácia neutralizadora do SARS-CoV-2.

Em decorrência dos estudos apresentados, Wu et al. é o único que que não apoia a amamentação e ressalta que as mães amamentem apenas quando estiverem completamente recuperadas, isso até que estudos maiores comprovem a segurança do leite materno. Os demais estudos, cujos os testes nos leites foram testados positivamente e nos quais não foram encontradas evidências de RNA do SARS-CoV-2, consideram que a amamentação não representa perigo e apoiam a promoção da prática mesmo em decorrência da pandemia.

Dessa forma a OMS (2020) juntamente com o Ministério da Saúde (2020) aconselham as mães que estão infectadas a realizarem a amamentação de forma segura seguindo os cuidados necessários.

\section{Conclusão}

Tendo em vista os fatos mencionados, pode-se concluir que estudos que evidenciaram a presença do RNA do SARSCoV-2 nos leites maternos, não foram expressados corretamente a forma como a coleta dos leites foi feita, não excluindo assim a possibilidade de os leites terem sidos contaminados no momento da coleta. No entanto, mesmo o vírus sendo detectado nessas amostras de leite, a sua proliferação é inviável, sendo a sua disponibilid ade excluída após 3 ou mais dias.

Apesar de 50\% dos artigos relatarem a presença do SARS-CoV-2 no leite materno, pode-se dizer que o aleitamento materno não é considerado um meio de transmissão vertical do coronavírus. Diante disso, faz-se necessário mais estudos com essa temática para melhor compreensão a cerca do tema, e assim, obter mais conhecimento e desenvolver estratégias efetivas na área.

\section{Referências}

Ahn, D. G., Shin, H. J., Kim, M. H., Lee, S., Kim, H. S., Myoung, J., \& Kim, S. J. (2020). Current status of epidemiology, diagnosis, therapeutics, and vaccines for novel coronavirus disease 2019 (COVID-19).

Bertino, E., Moro, G. E., De Renzi, G., Viberti, G., Cavallo, R., Coscia, A., \& Lembo, D. (2020). Detection of SARS-CoV-2 in milk from COVID-19 positive mothers and follow-up of their infants. Frontiers in Pediatrics, 8, 676.

Bi, Q., Wu, Y., Mei, S., Ye, C., Zou, X., Zhang, Z., \& Feng, T. (2020). Epidemiology and transmission of COVID-19 in 391 cases and 1286 of their close contacts in Shenzhen, China: a retrospective cohort study. The Lancet Infectious Diseases, 20(8), 911-919.

Chambers, C., Krogstad, P., Bertrand, K., Contreras, D., Tobin, N. H., Bode, L., \& Aldrovandi, G. (2020). Evaluation for SARS-CoV-2 in breast milk from 18 infected women. Jama, 324(13), 1347-1348. 
Chen, Lian et al. Clinical characteristics of pregnant women with Covid-19 in Wuhan, China. New England Journal of Medicine, v. 382, n. 25, p. e100, 2020.

Favre, G., Pomar, L., Qi, X., Nielsen-Saines, K., Musso, D., \& Baud, D. (2020). Guidelines for pregnant women with suspected SARS-CoV-2 infection. The Lancet Infectious Diseases, 20(6), 652-653.

Keppler, K. A., Machado, S. B., da Silva, R. C., Quiñones, E. M., \& dos Santos Giovanini, E. C. (2020). A importância do aleitamento materno nos primeiros anos de vida: uma revisão bibliográfica. Revista Higei@-Revista Científica de Saúde, 2(4).

Krogstad, P., Contreras, D., Ng, H., Tobin, N., Chambers, C., Bertrand, K., \& Aldrovandi, G. (2021). No evidence of infectious sars-cov-2 in human milk: analysis of a cohort of 110 lactating women. medRxiv.

Liu, W., Wang, J., Li, W., Zhou, Z., Liu, S., \& Rong, Z. (2020). Clinical characteristics of 19 neonates born to mothers with COVID-19. Frontiers of medicine, 14(2), 193-198.

Marín Gabriel, M. Á., Malalana Martínez, A. M., Marín Martínez, M. E., \& Anel Pedroche, J. (2020). Negative transmission of SARS-CoV-2 to handexpressed colostrum from SARS-CoV-2-positive mothers. Breastfeeding Medicine, 15(8), 492-494.

Melo, L. P. C. de., Dias, M. E. da S., Santana, M. S. ., Diniz, P. R. ., Galvão, P. V. M., \& Santana, P. de M. S. . (2020). Breastfeeding in covid-19 times: an integrative review. Research, Society and Development, 9(9), e129997074.

Mota, L. P., Barbosa, V. de S., Carvalho, V. M. de, Nunes, E. de C., Sousa, M. J. F. de, Madureira, G. N., Castro, V. L. de, Rodrigues, F. de S., Rodrigues, G. R. S., Oliveira, Y. M. M. S., Mourão Neto, J. W. V., Soares, J. M., Barbosa, C. E. P., Pereira, A. O., Oliveira, C. R. de, \& Alves, V. K. de M. (2020). Clinical and laboratory characteristics of Covid-19 infection. Research, Society and Development, 9(7), e109973656.

Pace, R. M., Williams, J. E., Järvinen, K. M., Belfort, M. B., Pace, C. D., Lackey, K. A., \& McGuire, M. K. (2021). Characterization of SARS-CoV-2 RNA, antibodies, and neutralizing capacity in milk produced by women with COVID-19. Mbio, 12(1), e03192-20.

Secretaria de Atenção à Saúde. Ministério da Saúde. (2015). Estratégia nacional para promoção do aleitamento materno e alimentação complementar saudável no Sistema Único de Saúde: manual de implementação.

Santos, R. C. dos ., Amaral, R. C. C. ., Santos, E., Carvalho, T. V. ., Correia, T. L. B. V. ., Costa, C. M. da ., Pena, H. P. ., Rodrigues, S. B. ., \& Andrade , S. N. . (2021). Exclusive breastfeeding in COVID-19 pandemic times: integrative review. Research, Society and Development, $10(3)$, e28310313167.

OMS. Amamentação e COVID-19: resumo científico. Genebra, Suiça, 2020. https://www.who.int/news-room/commentaries/detail/breastfeeding-and-covid19.

OMS. COVID 19: recomendações da OMS para assegurar o contato mãe-bebê depois do parto e no aleitamento materno. Instituto Europeu de Saúde Mental Perinatal, 2020. Disponível em: https://saudementalperinatal.com/covid-19-recomendacoes-da-oms-para-assegurar-o-contato-mae-bebe-depois-do-parto-e-noaleitamento-materno/.

Wu, Y., Liu, C., Dong, L., Zhang, C., Chen, Y., Liu, J., ... \& Huang, H. (2020). Coronavirus disease 2019 among pregnant Chinese women: case series data on the safety of vaginal birth and breastfeeding. BJOG: An International Journal of Obstetrics \& Gynaecology, 127(9), 1109-1115.

WHO, World Health Organization. Coronavirus disease (COVID-19) situation reports. 2021. https://www.who.int/publications/m/item/weeklyepidemiological-update-on-covid-19---11-may-2021.

WHO, World Health Organization. Breastfeeding and COVID-19 Available. Who, 2020. https://www.who.int/publications/i/item/WHO-2019-nCoVSci_Brief-Breastfeeding-2020.1. 